\title{
Sensory Function and Gating of Histaminergic Neuron C2 in Aplysia
}

\author{
Klaudiusz R. Weiss, ${ }^{\star}$ Hillel J. Chiel, ${ }^{1}$ and Irving Kupfermann $\dagger$ \\ Center for Neurobiology \& Behavior, The New York State Psychatric Institute, New York, New York 10032, \\ Departments of †Physiology, ${ }^{*}$ Anatomy and Cell Biology, and *†Psychiatry, " $†$ Columbia University College of \\ Physicians and Surgeons, and *School of Dental and Oral Surgery, New York, New York 10032
}

\begin{abstract}
This paper explores the possible sensory function of the identified histaminergic neuron C2. Mechanical stimulation of a narrow region around the mouth of the animal (perioral zone) elicits brief depolarizing potentials in C2. Extracellular recordings from the peripheral axons of $\mathrm{C} 2$ indicate that the depolarizing potentials are due to action potentials that are conveyed from the periphery but do not invade the cell body, since they fail at a region with a low safety factor within the cerebral ganglion. These blocked axonal spikes (A-spikes) function as if they were excitatory synaptic inputs to $C 2$, since the synaptic output of $\mathrm{C} 2$ does not occur unless the A-spikes succeed in evoking full action potentials in the soma (or an electrically close initial segment) of $\mathrm{C} 2$. Furthermore, like synaptic potentials, the A-spikes exhibit temporal and spatial summation, and facilitation. $\mathrm{C} 2$ receives both tonic and phasic inhibitory synaptic potentials, which can decrease the summation of A-spikes and thereby alter the frequency-filtering properties of $\mathrm{C} 2$ or block its synaptic output. Thus, $\mathrm{C} 2$ appears to be an unusual proprioceptive afferent that has a high degree of integrative function and may provide critical gating that is dependent on a variety of external and internal conditions.
\end{abstract}

In previous work (Weiss et al., 1986a, b), we provided evidence that the identified histaminergic neuron C2 of Aplysia fires during a feeding motor program and provides slow excitatory synaptic input to the metacerebral cell (MCC), a neuron that executes aspects of a food arousal state in the animal. The data suggest that $\mathrm{C} 2$ is an element of the circuits involved in mediating the food arousal state. During feeding motor programs, $\mathrm{C} 2$ exhibits depolarizing potentials that summate and drive the cell into a high-frequency burst of spikes. Although these depolarizing potentials are evoked by food stimuli, they are not directly dependent upon this chemosensory stimulation, since they continue to occur for a period of time after the chemosensory stimulation is terminated. In the present paper, we explore 2 questions: (1) what provides the excitatory potentials to $\mathrm{C} 2$, and (2) how might the activity of $\mathrm{C} 2$ be modulated? We provide evidence that $\mathrm{C} 2$ is a mcchanoafferent ncuron that can monitor some aspect of the feeding behavior of the animal. Furthermore, the synaptic output of $\mathrm{C} 2$ appears to be gated in an all-or-none fashion by inhibitory synaptic input and by electrotonically transmitted axon spikes that function like excitatory input to

\footnotetext{
Received Oct. 22, 1985; revised Feb. 18, 1986; accepted Feb. 20, 1986.

We wish to thank Drs. T. W. Abrams, T. J. Carew, V. F. Castellucci, E. R. Kandel, and J. Koester for their comments and discussions. This work was supported in part by PHS Grants MH35564, GM320099, and RSDA MH00304.

Correspondence should be addressed to Dr. I. Kupfermann, Center for Neurobiology \& Behavior, 722 West 168 th Street, Psychiatric Institute Annex-8th floor, New York, NY 10032.

${ }^{1}$ Present address: Bell Laboratories, 600 Mountain Avenue, Murray Hill, NJ 07974.
}

Copyright $(\overline{\mathcal{C}}) 1986$ Society for Neuroscience $0270-6474 / 86 / 082416-11 \$ 02.00 / 0$ the cells. Some of these results have appeared in a preliminary communication (Weiss et al., 1983).

\section{Materials and Methods}

The electrophysiological methods used in this study were standard techniques, previously described. Intracellular recordings were obtained by means of double-barrel microelectrodes filled with $2 \mathrm{M}$ potassium citrate. Three types of preparations were used: (1) semi-intact, (2) reduced, and (3) isolated nervous system. The semi-intact preparation (Weiss et al., 1986b) consisted of the isolated head in which the buccal artery was perfused with cooled seawater $\left(15^{\circ} \mathrm{C}\right)$. The cerebral ganglion was pinned to a transilluminated stage and desheathed in order to expose $\mathrm{C} 2$ and the MCC. The reduced preparation consisted of the isolated cerebral ganglion, together with one or more lip nerves connected to the anterior tentacles, mouth, and jaws. In some experiments, an inflatable rubber "balloon" was inserted into the mouth in order to provide a reproducible mechanical stimulus to the jaws and perioral zone (Fig. 1). The balloon was constructed of a thin-walled rubber finger cot, and was inflated by means of seawater injected through a polyethylene tube that was tied into the open end. In order to monitor the inflation of the balloon, pressure in the tube was measured by a Statham pressure gauge. Extracellular nerve recordings were made en passant by means of a doublemembrane electrode (Koch et al., 1984) or a polyethylene suction electrode into which a loop of nerve was drawn. The isolated preparation consisted of the cerebral ganglion connected only to the buccal ganglion, with all peripheral structures removed.

Chemical synaptic transmission was blocked by a solution containing reduced $\mathrm{Ca}^{2+}$ concentration $(0.5 \times$ normal, $5 \mathrm{mM})$ and increased $\mathrm{Mg}^{2+}$ concentration $(4 \times$ normal, $200 \mathrm{~mm})$.

\section{Results}

\section{C2 is excited by mechanostimulation of the perioral zone}

We have previously found that in the isolated head preparation one could record excitatory potentials in $\mathrm{C} 2$ during one phase of the feeding motor program (Weiss et al., 1986b). We showed that these excitatory potentials could be elicited by mechanical stimulation of the lip area, and that the amplitude of the potentials decreased as the cells were hyperpolarized. These observations were consistent with a hypothesis that the excitatory potentials were blocked axon spikes (A-spikes), and that cell $\mathrm{C} 2$ was an afferent neuron. In the first series of experiments designed to test this hypothesis, we attempted to determine if these excitatory potentials were due to central neurons that were excited during activation of central programs, or were associated with afferent input from the periphery. We eliminated all afferent input by using a preparation consisting of the isolated cerebral ganglion connected to the buccal ganglion. Rhythmic motor programs were elicited by stimulating the esophageal nerve at $1 \mathrm{~Hz}$. In 10 preparations, such stimulation regularly evoked widespread activity in the buccal ganglion and in numerous cells in the E cluster of the cerebral ganglion. This activity probably reflected egestive, rather than ingestive, responses, but the esophageal nerve was used because, of all of the nerves, it evokes the most reliable and vigorous rhythmic output. Although C2 


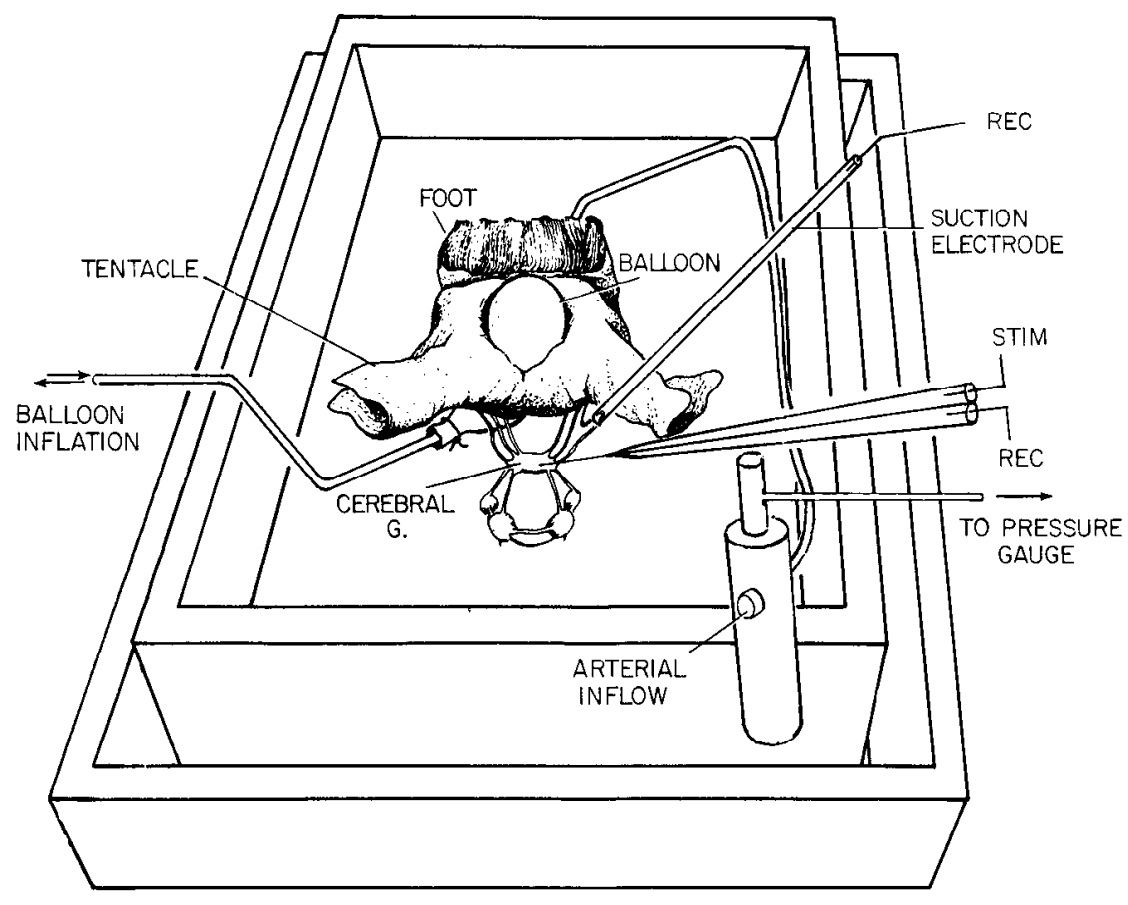

Figure 1. Semidiagrammatic representation of the reduced preparation used to stimulate the lips and the perioral zone while recording intracellularly from the cells in the cerebral ganglion (cerebral g.), and recording extracellularly from peripheral nerves. Pressure on the tissues of the buccal mass was measured by recording the pressure of the arterial inflow, as described by Weiss et al. (1986b). In some preparations in which the receptive field was explored with a blunt probe, the mouth balloon was not used.

received inhibitory input during such patterned activity, fast excitatory potentials were never seen (Fig. 14 in Chiel et al., 1986), which supports the idea that these potentials may arise in association with peripheral afferent activity.

\section{Receptive field}

To determine the area of stimulation that produced responses in $\mathrm{C} 2$, we used the isolated head preparation and applied mechanical or seaweed stimuli to various regions of the head using probes, a mouth balloon (see Fig. 1 and Materials and Methods), or pieces of seaweed (Laver). Consistent with our previous results (Weiss et al., 1986a, b), mechanical stimuli evoked responses in $\mathrm{C} 2$, and all short-latency responses evoked by seaweed appeared to be due to the mechanostimulatory properties of the stimulus. Gentle stimulation with a probe of the tissue immediatcly around the mouth croked fast potentials in $\mathrm{C} 2$ even when there was no sign of a rhythmic motor program (Fig. 2 ). With a maintained stimulus provided by the inflated balloon, C2 exhibited a train of spike activity (Fig. $2 B$ ).

The reduced preparation permitted more detailed mapping of the receptive field of $\mathrm{C} 2$. Mechanical stimuli were effective only when applied to a narrow band of tissue around the mouth, i.e., the perioral zone (Rosen et al., 1982). Pressure stimuli produced by a blunt probe (fire-polished Pasteur pipette) were effective when applied to either the internal or external surface of the perioral zone. Pulling on muscle fragments inserted into the perioral region was not effective in eliciting A-spikes. Details of the projection zones of each of the nerves were not studied, but we established that the posterior lip nerve innervated only the posterior (caudal) region of the perioral zone, since this region remained sensitive to mechanical stimulation when all nerves were cut, except for the posterior lip nerve.

\section{The depolarizing potentials in $\mathrm{C} 2$ are due to blocked axon spikes}

The depolarizing potentials in $\mathrm{C} 2$ that occurred in response to mechanical stimulation of the perioral zone, or during feeding in the semi-intact preparation, have an unusually fast rise time. Furthermore, the fast potentials that occur in the isolated head preparation were reduced when $\mathrm{C} 2$ was hyperpolarized (Weiss et al., 1986b). These data suggest that the fast potentials are not chemical excitatory synaptic potentials but, rather, electrotonically conducted A-spikes that are conducted from the periphery and fail before invading the soma or initial axon. To test this, we examined the excitatory potentials evoked by mechanical stimulation at different levels of $\mathrm{C} 2$ membrane potential in a reduced preparation. As would be expected for an A-spike, hyperpolarization of $\mathrm{C} 2$ always reduced (Fig. $2 A$ ), and in some cases eliminated, the potentials. We next strongly reduced or blocked chemical synaptic transmission by a low $\mathrm{Ca}^{2+}(5 \mathrm{~mm})$, high $\mathrm{Mg}^{2+}(200 \mathrm{~mm})$ solution and found that brief mechanical stimulation of the perioral region still evoked a fast prepotential that could be reduced in size by hyperpolarizing $\mathrm{C} 2$ (Fig. $2 A_{2}$ ). In the presence of a low $\mathrm{Ca}^{2+}$, high $\mathrm{Mg}^{2+}$ solution, the depolarizing response showed a reduced rate of rise. The reason for this is unknown, but may reflect the effect of the presence of a significant calcium component on the response in normal seawater, which is absent in low $\mathrm{Ca}^{2+}$, high $\mathrm{Mg}^{2+}$, solution. Although $\mathrm{C} 2$ exhibited a small reduction of input resistance when hyperpolarized (anomalous rectification), a substantial decrease in the size of its prepotentials was produced by hypcrpolarization within a range (10-20 mV) in which little or no alteration of input resistance occurred. Similar results were obtained when a maintained stimulus was applied to the perioral zone. In normal seawater, we recorded a series of fast potentials that could summate to produce an action potential (Fig. $2 B_{1}$ ). In the low $\mathrm{Ca}^{2+}$, high $\mathrm{Mg}^{2+}$ solution, the prepotentials could still be evoked, although mechanical stimulation of the perioral zone was less effective in this solution than in normal seawater, i.e., the threshold appeared to be elevated. This was consistent with observations made on several types of mechanoafferents in Aplysia (Byrne et al., 1974; Rosen et al., 1979) in which perfusion with solutions with a high magnesium content increased the threshold of the mechanoafferents. Our results support the suggestion that the prepotentials in $\mathrm{C} 2$ are electrotonically conducted $\mathrm{A}$-spikes that are initially generated at the terminals of the axons of C2 in the perioral zone, and are conducted centrally, but fail to invade the cell body since they are presumably blocked at a region of low safety factor in the cerebral ganglion (see Fig. 4). Since the prepotentials are also evoked when the preparation is 

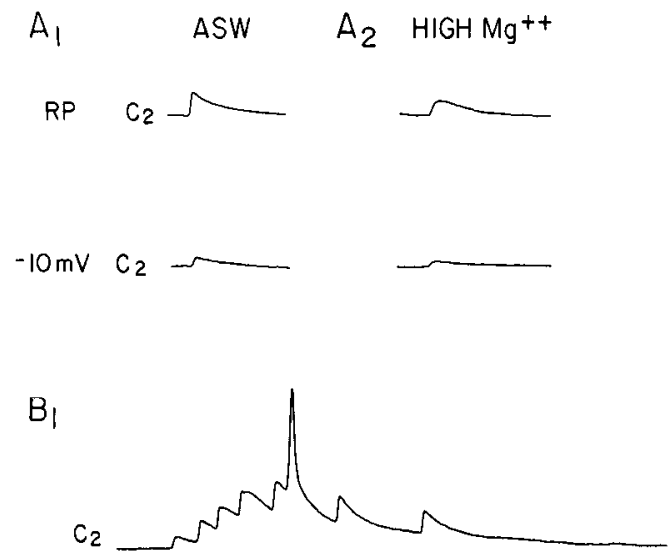

$\mathrm{B}_{2}$

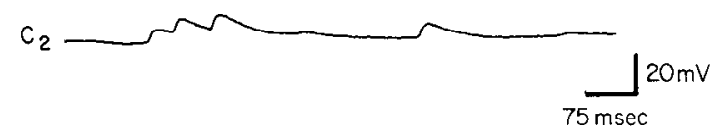

Figure 2. Properties of the response of neuron C2 to peripheral stimulation of the perioral zone. $A$, Very brief mechanical stimulation of the perioral zone with a probe, both in normal ASW $(A I)$ and in a solution containing $4 \times$ normal $\mathrm{Mg}^{2+}$ and $0.5 \times$ normal $\mathrm{Ca}^{2+}\left(A_{2}\right)$, produced a depolarizing potential characterized by a relatively fast rise time. When cell $\mathrm{C} 2$ was hyperpolarized $-10 \mathrm{mV}$ from the resting potential $(R P)$, the amplitude of the response decreased (lower row of recordings, $A_{1}$ and $A_{2}$ ). $B$, More prolonged mechanical stimulation of the perioral zone (using an inflated balloon) produced a burst of fast depolarizing potentials. In normal seawater $\left(B_{t}\right)$, the depolarizing potentials can summate and give rise to an action potential. $B_{2}$, The preparation was bathed in a solution of low $\mathrm{Ca}^{2+}$, high $\mathrm{Mg}^{2+}$ identical to that shown in $A_{2}$. Stimulation of the perioral zone produced a train of potentials of lower frequency than in $B_{l}$, presumably reflecting an increase of threshold in this solution.

in a solution that blocks chemical transmission, $\mathrm{C} 2$ appears to be a primary mechanoafferent neuron. We cannot, however, exclude the possibility that $\mathrm{C} 2$ is a secondary afferent whose peripheral terminals are excited by a primary sensory cell that is electrically coupled, or coupled by means of a chemical synapse that is protected from the low $\mathrm{Ca}^{2+}$, high $\mathrm{Mg}^{2+}$ solution. Either interpretation, however, predicts that the A-spikes in C2 would be associated with a spike in a peripheral ncrve, and that the peripheral spike conducts toward the cell body.

We, therefore, recorded en passant from peripheral nerves in a reduced preparation consisting of the lips, tentacles, mouth, and cerebral ganglion. Spikes were elicited in $\mathrm{C} 2$ by intracellular depolarization. The intracellular spike was always followed by a relatively large extracellular spike that appeared in the posterior lip nerve. Smaller spikes appeared in the medial and anterior lip nerves, which, compared to the posterior lip nerve, are of larger diameter and consequently provide a greater shunt for extracellular currents. Reproducible mechanical stimulation of the perioral zone was provided by inflating a balloon inserted into the mouth (see Fig. 1). Figure 3 shows a low-speed en passant recording from the posterior lip nerve and cell $\mathrm{C} 2$, together with a recording of the pressure used to monitor the inflation of the balloon. Inflation of the balloon resulted in a burst of activity recorded extracellularly in the nerve as well as in an increase of action potentials in $\mathrm{C} 2$ (Fig. 3A). In Figure $3 B$, a faster sweep speed indicates that for each intracellularly recorded action potential there is a corresponding extracellular spike. In $3 C$, superimposed traces (three sweeps in each case) for intracellular and extracellular records are shown. The extracellularly recorded action potentials are identical when the spike
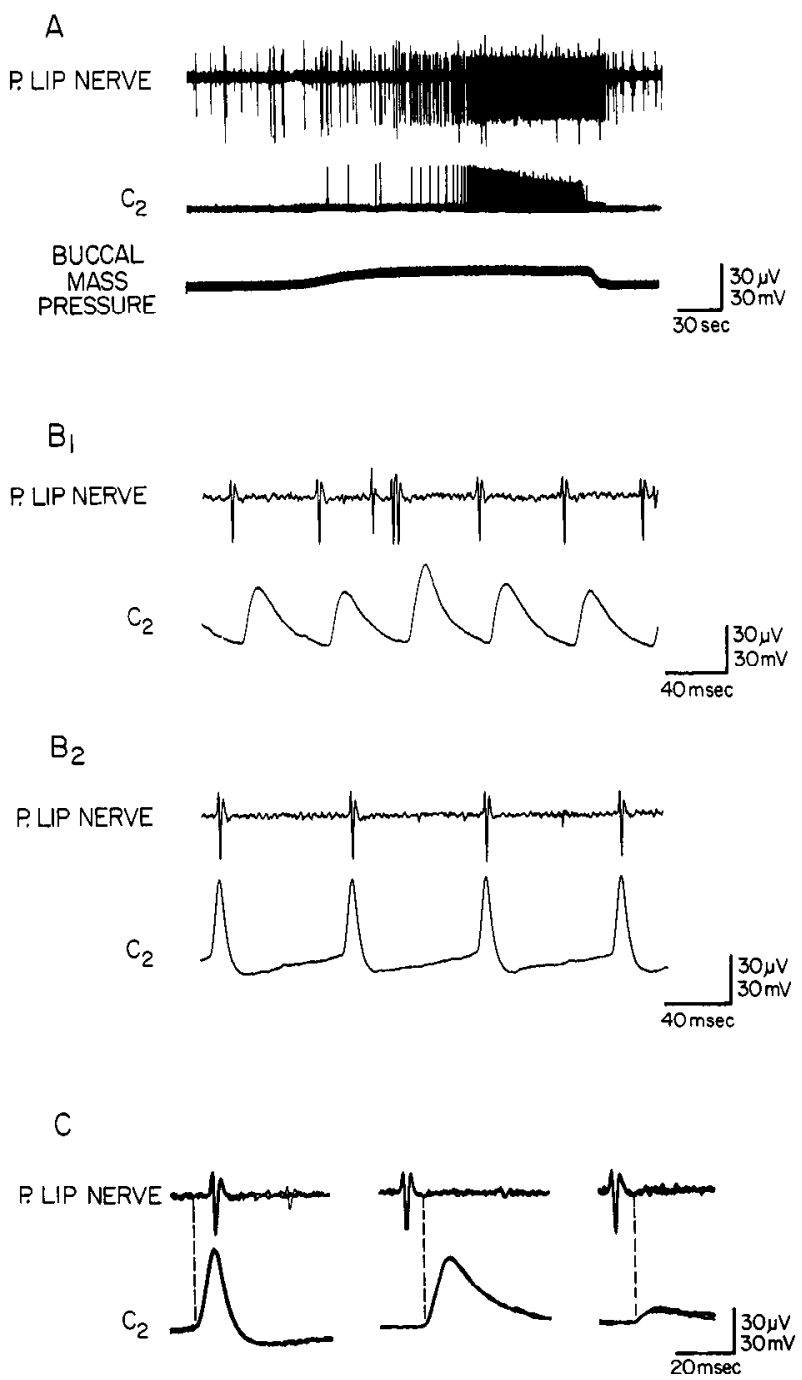

Figure 3. Direction of propagation of $\mathrm{C} 2$ action potential in the posterior lip nerve. $A$, Low-speed intracellular recording from neuron $\mathrm{C} 2$, simultaneous with an extracellular recording from the posterior $(p$.) lip nerve. Arterial pressure of the buccal mass was used to monitor the filling of the balloon, which served to stimulate the jaws and the perioral zone of the animal. $B_{l}$, Higher-speed recording of the section of the record illustrated in $A$. Note the one-for-one potentials in the soma of $\mathrm{C} 2$ and in the posterior lip ncrve. Occasional cxtracellular spikes that did not correlate with potentials in $\mathrm{C} 2$ were also seen. These spikes had different waveforms from those that correlated with $\mathrm{C} 2$ activity and may reflect the axonal spikes of neurons homologous to C2. $B_{2}$, Extracellularly recorded potential in the posterior lip nerve in response to intracellular stimulation of $\mathrm{C} 2$. $C$, Superimposed traces comparing the latency of the somatic and peripheral action potentials of $\mathrm{C} 2$. The pair of recordings on the left show that when the peripheral action potential was evoked by intracellular stimulation of cell $\mathrm{C} 2$, the rising phase of the somatic action potential preceded the peripheral action potential. When the action potentials were evoked by mechanical stimulation of peripheral tissues (middle traces), the rising phase of the somatic action potentials followed the peripherally recorded potentials. When mechanical stimulation evoked spikes while $\mathrm{C} 2$ was hyperpolarized (right traces), the potentials recorded in the soma were reduced, indicating that they were A-spikes rather than synaptic potentials.

is triggered intracellularly (left trace) or when it is triggered by stimulation of the mouth (middle trace). When a somatic spike is initiated by direct depolarization, the rising phase of the somatic spike precedes the extracellular spike recorded in the nerve (left trace). By contrast, when spikes are initiated by mechanical 

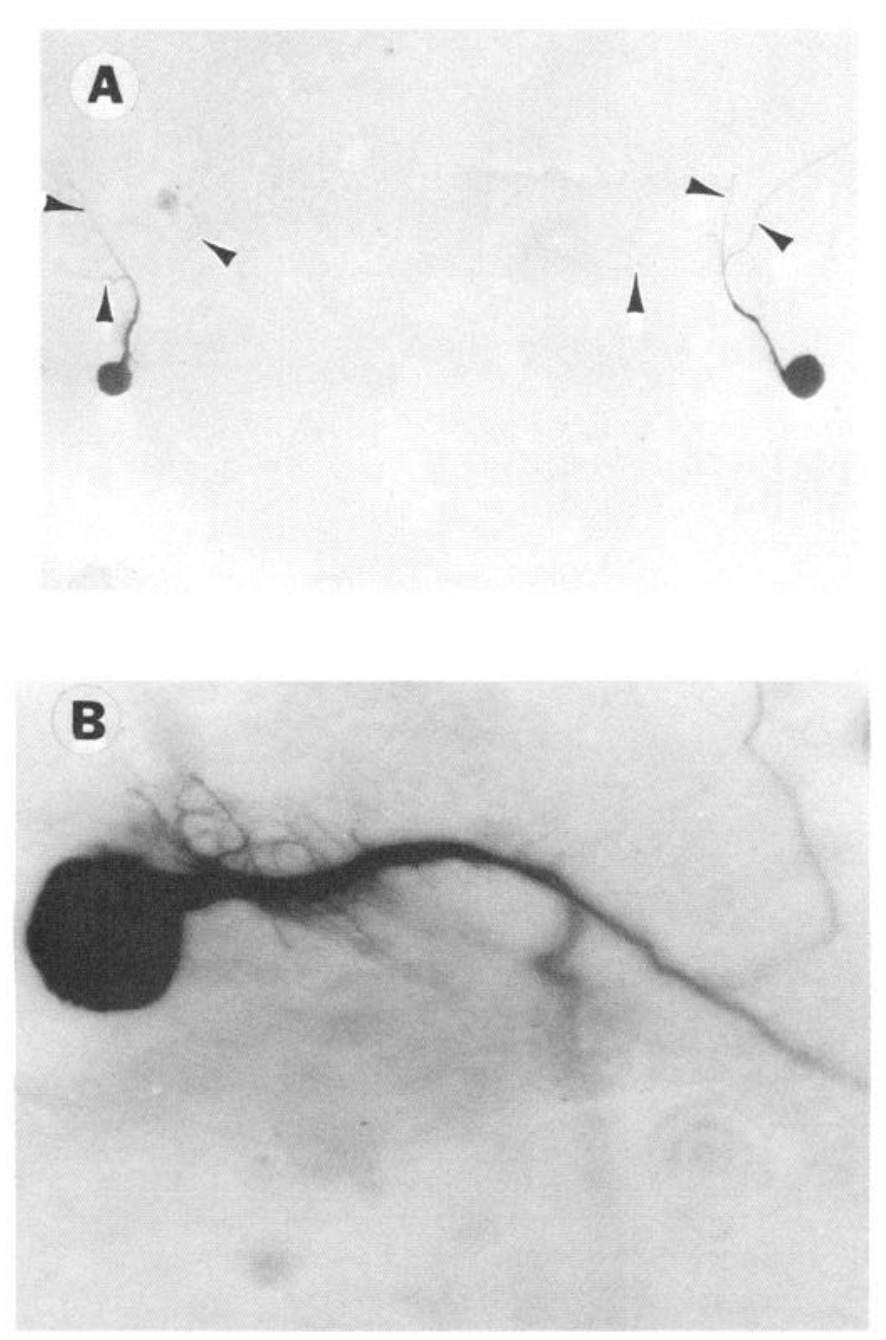

Figure 4. Morphology of $\mathrm{C} 2$ as revealed by intracellular injection of cobalt chloride, followed by precipitation with ammonium sulfide. $A$, Low-power view of the left and right $\mathrm{C} 2$ in a cerebral ganglion. Distance between cells, $1.6 \mathrm{~mm}$. The 3 axons of $\mathrm{C} 2$ are indicated by arrows. $B$, Closeup of the right $\mathrm{C} 2$, showing its 3 fine peripheral axons, its initial stout process, and fine processes emanating from the stout process. Diameter of cell body, $100 \mu \mathrm{m}$.

stimulation of the mouth, the extracellular spike in the nerve precedes the somatic potentials (middle trace), indicating that the extracellular spike is conducted in the opposite direction, i.e., from the periphery towards the ganglion. The recording on the right side of Figure $3 C$ illustrates that when $\mathrm{C} 2$ is hyperpolarized, the intracellular potential that is evoked by stimulation of the mouth is decreased in amplitude, indicating that it is indeed an A-spike.

\section{Morphology of $C 2$}

In order to gain some insights into the functional properties of $\mathrm{C} 2$, its gross morphology was ascertained by pressure-injecting it with cobalt acetate and developing this in ammonium sulfide. Consistent with previous anatomical studies (Gotoh and Schwartz, 1982; Weinreich, 1978), we found that C2 sent 3 axons to peripheral nerves - the posterior lip nerve, the medial lip nerve, and the anterior lip nerve (Fig. $4 A$ ). The cell body of $\mathrm{C} 2$ gave off a stout process containing numerous fine processes (Fig. $4 B$ ). The stout process ran toward the periphery of the ganglion and abruptly narrowed at a point where it bifurcated or trifurcated. In those cells that bifurcated, a second bifurcation

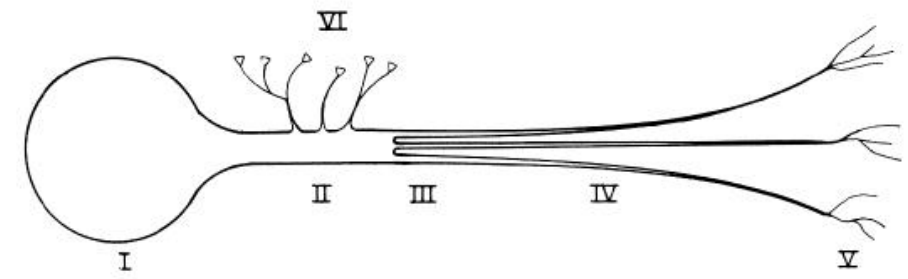

Figure 5. Schematic diagram of structure of $\mathrm{C} 2$ showing the functional regions discussed in the text: the soma $(I)$, the initial, large-diameter axon $(I I)$, the region in which the initial axon divides $(I I I)$ into fine peripheral process $(I V)$, the mechanoreceptive region of the axon $(V)$, and fine central synaptic processes $(V I)$ that emanate from the initial axon.

occurred shortly thereafter. An occasional fine process was seen emanating from axons at a point peripheral to where they had separated from the main, large axonal process, but the great majority of fine processes emanated from the stout segment between the soma and the bi- or trifurcation. This arrangement presumably accounted for the observation that the synaptic output of $\mathrm{C} 2$ was dependent upon the presence of a full spike in the initial segment or soma, as is described in a later section. Figure 5 is a schematic diagram of the structure of $\mathrm{C} 2$, illustrating its main functional regions.

\section{Synapse-like properties of the A-spike}

Although our evidence indicates that the fast prepotential that appears in $\mathrm{C} 2$ is an A-spike, we found that in some ways the A-spike functions like a conventional chemical excitatory synaptic potential. When the peripheral axon was electrically stimulated at high frequency, the A-spikes showed temporal summation, which resulted in the cell's reaching threshold. Once threshold was reached, the cell did not show appreciable adaptation, and continued to exhibit soma spikes, although, at intermediate frequencies of stimulation, every other A-spike might elicit a soma spike (Fig. 6A). Probably contributing to the relatively sharp threshold between no spikes and the substantial driving of somatic spikes was the presence of a positive afterpotential in $\mathrm{C} 2$. In fact, if the cell was brought close to firing threshold by means of intracellular depolarization, 1 or 2 antidromic spikes (or directly elicited spikes) could set $\mathrm{C} 2$ into a prolonged burst of spikes (Fig. $6 \mathrm{~B}$ ). The burst of spikes was associated with a cumulative slow depolarization that summated for $3 \mathrm{sec}$ and then reached a steady state level.

In addition to temporal summation, the fast prepotentials in C2 exhibited spatial summation. Figure 7 presents recordings from the soma of $\mathrm{C} 2$ when pairs of single shocks were presented, first, to the anterior lip nerve and then, after various intervals, to the posterior nerve. The first line shows the A-spikes elicited when either the anterior or posterior lip nerve alone was shocked. The subsequent traces show that, as the interval between shocks to the 2 nerves was reduced, the A-spikes exhibited temporal summation. When the interval was reduced to $1 \mathrm{msec}$, the A-spikes summated to threshold and initiated a full action potential.

A train of A-spikes in C2 exhibited not only summation, but facilitation, a form of plasticity. The facilitation ratio (initial magnitude/final magnitude) was highly sensitive to the membrane potential of $\mathrm{C} 2$, and the function relating facilitation ratio to membrane potential was complex. Figure 8 portrays the summation and facilitation of A-spikes as a function of the various membrane potentials at which $\mathrm{C} 2$ was held. The degree of facilitation of A-spikes clearly increased as the cell was progressively depolarized. Although superficial inspection of the raw data might suggest that the facilitation ratio smoothly increased as the cell was depolarized, a graph of the data (Fig. 9, upper graph) indicates sharp discontinuities in the function. Since C2 
$A$

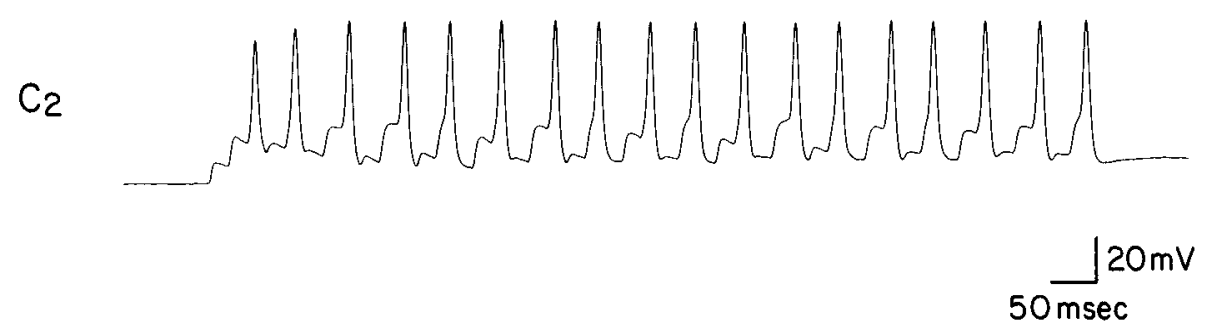

Figure 6. Activation of somatic spikes in neuron $\mathrm{C} 2$ by repetitive stimulation of a peripheral nerve. $A$, Stimulation of the posterior lip nerve produced A-spikes in the soma of $\mathrm{C} 2$. These A-spikes summated to produce action potentials that, at this frequency, follow every other A-spike. $B$, When $\mathrm{C} 2$ was depolarized by intracellular current, a single brief shock to the posterior lip nerve elicited an antidromic spike, followed by a prolonged burst of action potentials in $\mathrm{C} 2$. Note the slow cumulative depolarization that may account for the prolonged spike activity.

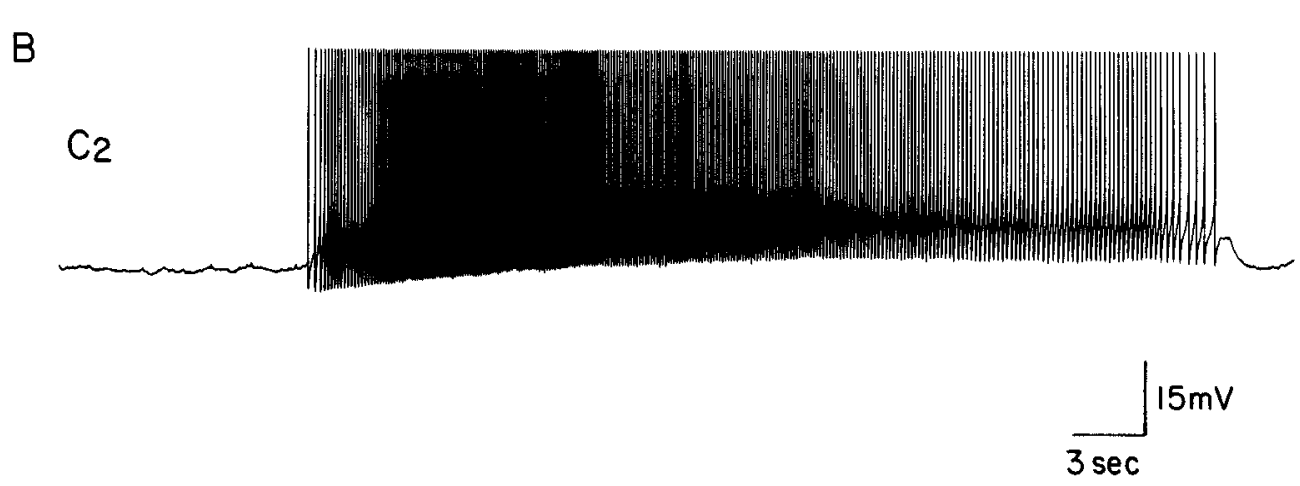

does not show step nonlinearities in its I-V curve, these discontinuities appear to be due to the appearance of step changes in the A-spike magnitude as the cell reached critical levels of membrane potential. This is revealed by the lower graph in Figure 8, which shows the sizes of the initial and final A-spikes used to determine the facilitation ratios. When the cell was maintained at strongly hyperpolarized membrane potentials of

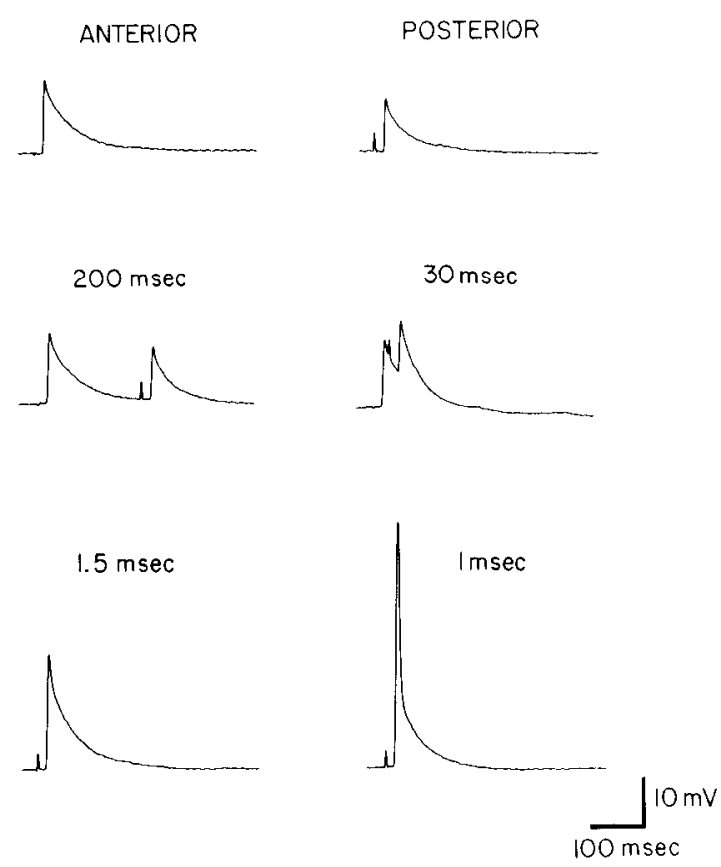

Figure 7. Spatial summation of A-spikes in $\mathrm{C} 2$. The lefl and right upper traces show the A-spikes produced by stimulation, respectively, of the anterior and posterior lip nerve alone. Subsequent traces show the effect of paired stimulation of the anterior lip nerve, followed by stimulation of the posterior lip nerve. As the interstimulus interval decreases, the $2 \mathrm{~A}$-spikes show increasing summation, and with a 1 msec interval they summate sufficiently to elicit a full-size somatic action potential.
-80 to $-85 \mathrm{mV}$, the initial A-spike was small and showed no facilitation (first trace, Fig. 8; last points, Fig. 9, lower graph). In the range between -85 and $-70 \mathrm{mV}$, the initial A-spike slightly increased with progressive background depolarization. The final A-spike, however, exhibited a dramatic increase over its initial value when the membrane potential was held very hyperpolarized. This was a result of a step increase of the amplitude of the A-spike within the train of A-spikes. As the cell was increasingly depolarized by intracellular current, the summating A-spikes brought it more rapidly to the critical threshold for the step increase. For example, for the experiment shown in Figure 8 , when $\mathrm{C} 2$ was at $-75 \mathrm{mV}$, the step increase of the A-spike occurred at the fourth shock, whereas, at $-70 \mathrm{mV}$, the step occurred at the second shock. With sufficient background depolarization, the first A-spike was already facilitated (Fig. 8, $-65 \mathrm{mV}$ ). This accounts for the step change of the initial A-spike amplitude shown in Figure 9, lower graph. In addition to the step changes of A-spike magnitude, depolarization also produced a graded increase in the magnitude of the final A-spikes (Fig. 9, lower part). We interpret these findings as most likely resulting from the following sequence: As the cell is depolarized, cither by the summating A-spikes or by background depolarization, the region where the A-spike is blocked moves closer to the cell body. In addition, new axonal branches are brought to threshold, resulting in step increases in the size of the A-spikes.

The facilitation of A-spikes might conceivably be due to an underlying slow decreased conductance EPSP. To investigate this, we compared the facilitation of the A-spikes in artificial seawater (ASW) and in ASW with $10 \mathrm{mM} \mathrm{Co}^{2+}$. Although the $\mathrm{Co}^{2+}$ blocked synaptic transmission in the ganglion (Fig. 10B), it did not significantly alter the facilitation of A-spikes (Fig. $10 \mathrm{~A}$ ), which suggests that the facilitation was not due to an underlying chemical synaptic potential.

\section{Gating of synaptic output of $C 2$}

The fact that the A-spikes seen in C2 exhibit spatial and temporal summation, as well as facilitation, probably would not be of functional significance if the output of $\mathrm{C} 2$ were a direct reflection of its axonal input. In other words, if an A-spike were as effective as a somatic spike in conveying the synaptic effects of $\mathrm{C} 2$, the synapse-like properties of the A-spike in $\mathrm{C} 2$ would 


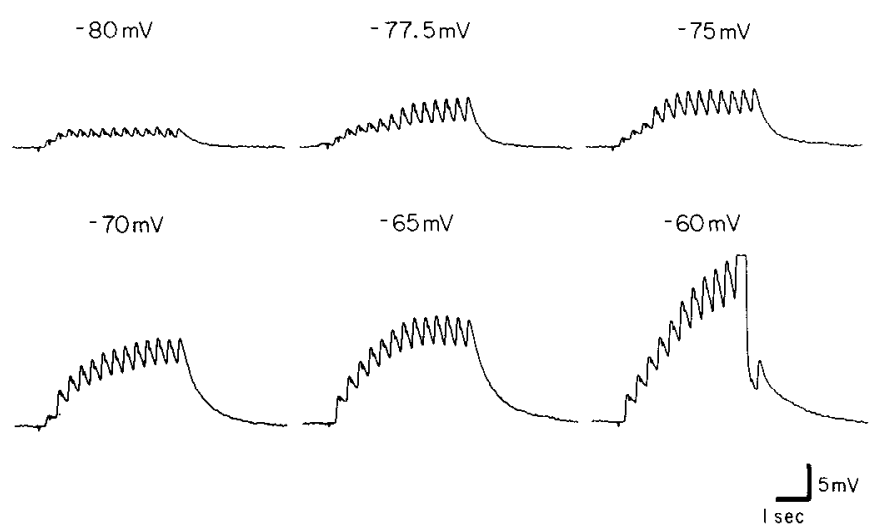

Figure 8. Temporal summation of A-spikes in neuron $\mathrm{C} 2$. The posterior lip nerve was stimulated with trains of shocks to produce trains of A-spikes in $\mathrm{C} 2$. The membrane potential of $\mathrm{C} 2$ was brought to different levels by intracellular injections of current. The amplitude and facilitation of the A-spikes increased as the cell was held at increasingly depolarized levels. When the cell was brought to its resting potential $(-60 \mathrm{mV})$, the summating A-spikes depolarized the cell to its threshold and the cell fired an action potential (top of spike cut off by pen recorder).

be irrelevant to its function. On the other hand, the somatic spike probably reflects invasion of the A-spike into the large main process (Fig. 4) that contains the fine processes that presumably convey the synaptic output of C2 (Bailey et al., 1982). We therefore examined whether the presence or absence of somatic spikes correlated with variation of the synaptic effects of $\mathrm{C} 2$ on its follower cells. We examined inhibitory followers as well as excitatory followers of $\mathrm{C} 2$. Figure 11 gives the results of such an experiment; we electrically stimulated the posterior lip nerve which contains an axon of $\mathrm{C} 2$. The frequency and duration of stimulation were within the lower range of what normally occurs, and were selected so that, when $\mathrm{C} 2$ was at resting potential, the A-spikes did not summate sufficiently to produce full-size action potentials in the soma. As is shown in Figure $11 \mathrm{~A}$, when only A-spikes were recorded in the soma, there were no obvious synaptic potentials in an inhibitory follower (IF) of cell $C 2$. Figure $11 B$ shows that hyperpolarization of $\mathrm{C} 2$ resulted in a decrcasc of dcpolarizing responses in $\mathrm{C} 2$, confirming that the potentials were indeed A-spikes rather than synaptic potentials. In this case also, no postsynaptic potentials were recorded in the inhibitory follower. However, when cell C2 was depolarized by $10 \mathrm{mV}$, so that individual A-spikes produced onefor-one full action potentials in C2 (Fig. 11D), a slow inhibitory potential occurred in the inhibitory follower cell. The presence of a synaptic potential could conceivably be due to the fact that C2 was depolarized, since C2 (Weiss et al., 1986a), as well as many other molluscan neurons (e.g., Shapiro et al., 1980; Shimahara and Tauc, 1975), exhibits enhanced release of transmitter when the cell is maintained with a background depolarization. To control for this, we held $\mathrm{C} 2$ at resting membrane potential and fired individual action potentials by injecting a series of $5 \mathrm{msec}$ current pulses. Under these conditions, we still observed inhibition of the follower cell (Fig. 11C). The inhibition was comparable to that produced by the somatic spikes evoked by A-spikes when $\mathrm{C} 2$ was depolarized. This indicates that the critical factor for the release of transmitter was the occurrence of full action potentials in the soma or main process, rather than the holding membrane potential per se.

Figure 12 gives the results obtained using the excitatory slow synaptic potential in the MCC as an index of the synaptic effects of $\mathrm{C} 2$. Again, we found little evidence for a synaptic effect of A-spikes in $\mathrm{C} 2$ in the absence of somatic spikes.
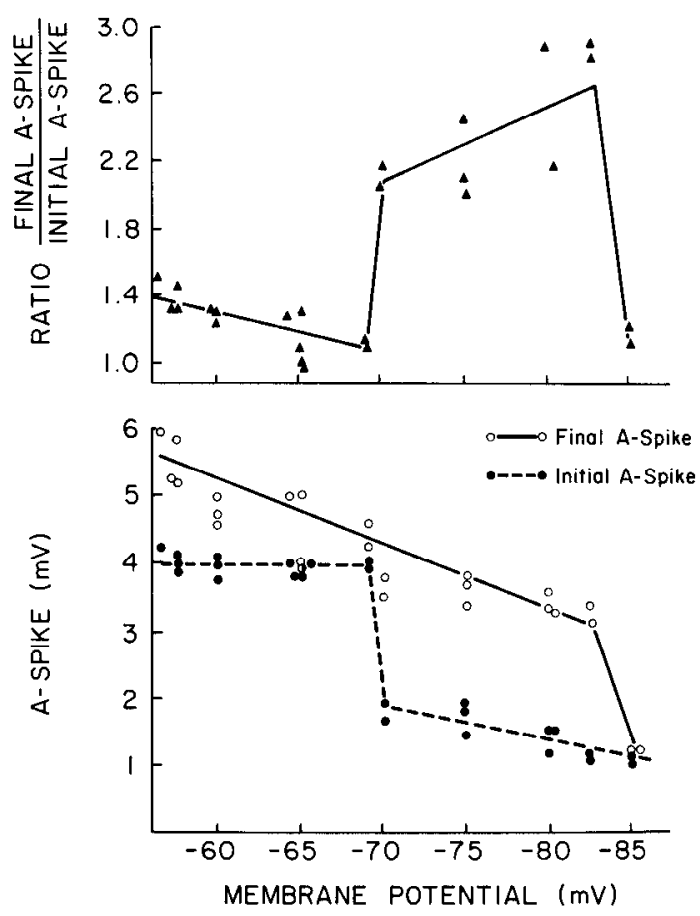

Figure 9. Facilitation of A-spikes in $\mathrm{C} 2$ as a function of membrane potential. $\mathrm{C} 2$ was held at different membrane potentials and trains of shocks were presented to the posterior lip nerve in order to elicit A-spikes (see Fig. 8 for experimental paradigm). Top graph shows the facilitation ratio as a function of the holding membrane potentials of C2. The facilitation ratio is the size of the final A-spike of the train, divided by the size of the initial A-spike. Each A-spike was measured from the point of rise to the peak size. The graph shows 2 sharp breaks. Bottom graph shows the actual size of the initial and final A-spikes and reveals that the breaks in the graph of facilitation ratios are due to one break in the initial A-spike function, and a second break in the final A-spike function.

\section{ASW}

Al

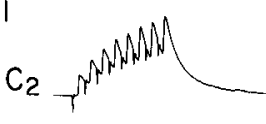

BI

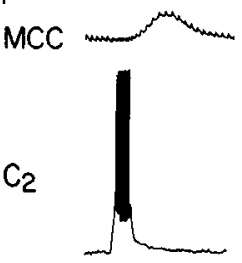

\section{$\mathrm{ASW}+10 \mathrm{mM} \mathrm{Co}^{++}$}

$A 2$

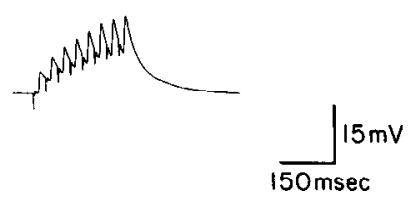

B2

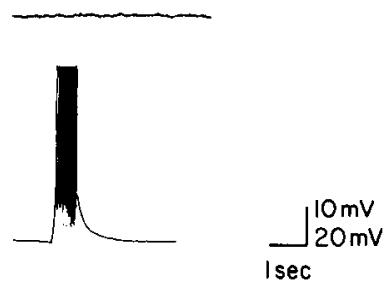

Figure 10. Effect of blocking chemical synaptic transmission on the summation and facilitation of $\mathrm{A}$-spikes in neuron $\mathrm{C} 2$. A-spikes were elicited by trains of stimulation of the posterior lip nerve. $A 1$, The preparation was bathed in seawater and the A-spikes showed their characteristic facilitation and summation. $A 2$, The bath contained seawater plus $10 \mathrm{~mm}$ cobalt ions, to block chemical synaptic transmission. The facilitation and summation of A-spikes was not significantly altered in this solution. $B$, Demonstration of the efficacy of cobalt in blocking chemical transmission in this preparation. $B 1$, When the preparation was bathed in a solution of seawater, a train of action potentials in neuron $\mathrm{C} 2$ produced a characteristic slow synaptic potential in the MCC. $B 2$, This potential was totally abolished when the preparation was bathed in seawater with cobalt. 


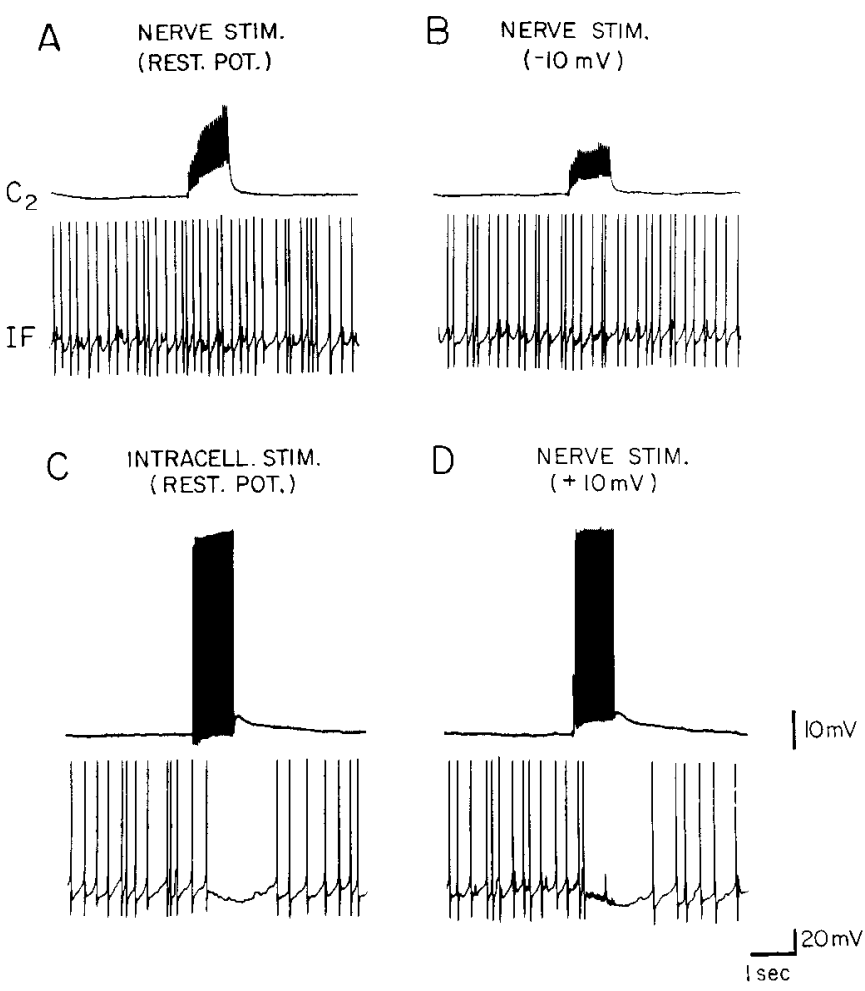

Figure 11. Effects of somatic spikes in neuron $\mathrm{C} 2$ on synaptic transmission to an inhibitory follower $(I F)$ of $C 2$. A train of electrical stimuli (NER VE STIM.) to the posterior lip nerve was used to produce A-spikes in $\mathrm{C} 2$. $A$, When $\mathrm{C} 2$ was held at resting potential (REST. POT.), the A-spikes did not bring the cell to its threshold for producing somatic spikes, and no synaptic potential was seen in the inhibitory follower of $C 2$. $B$, Neuron $C 2$ was hyperpolarized and the magnitudes of the fast potentials in $\mathrm{C} 2$ were reduced, indicating that they were A-spikes. Again, no inhibition was seen in the inhibitory follower cell. $C, \mathrm{C} 2$ was held at resting membrane potential and a burst of somatic spikes was produced by injecting brief intracellular current pulses (INTRACELL. $S T I M$.) so that each pulse produced a single action potential. The cell was driven at the same rate at which the A-spikes were elicited in the record shown in $A$. Under these conditions, a slow inhibitory synaptic potential was evoked in the inhibitory follower of C2. $D$, When $\mathrm{C} 2$ was depolarized by $10 \mathrm{mV}$, stimulation of the posterior lip nerve produced A-spikes, each of which evoked an action potential in the soma of $\mathrm{C} 2$. Invasion of the soma was accompanied by a slow inhibitory synaptic potential in the inhibitory follower cell.

\section{Synaptic modulation of somatic spike activity of $C 2$}

The above results indicate that the presence of a somatic spike correlates with the synaptic output of $\mathrm{C} 2$. This finding would have added significance if the spike activity of $\mathrm{C} 2$ could be modulated by synaptic input. We have occasionally observed what appeared to be a weak slow excitatory input to $\mathrm{C} 2$, but by far the most powerful and reliable modulation occurs by means of inhibitory input. Electrical stimulation of the esophageal nerve elicits a hyperpolarization in C2. This hyperpolarization is due to a chemically mediated IPSP, since it is associated with an increased membrane conductance and it reverses when $\mathrm{C} 2$ is hyperpolarized (Fig. 13A3). An IPSP also occurs in C2 spontaneously during an organized burst of a feeding motor program in the buccal ganglion (Fig. $13 B_{2,3}$ ). When either the evoked or spontaneous IPSP occurs, it greatly reduces the capacity for A-spikes to evoke somatic spikes. In part, this is a consequence of the fact that the IPSP hyperpolarizes C2 away from its firing threshold. In addition, and perhaps more important, the IPSP increases membrane conductance and greatly accelerates the decay of individual A-spikes. Thus, temporal and spatial sum- mations are greatly diminished. Furthermore, the apparent facilitation of the A-spikes is reduced, since this type of facilitation is related to the level of depolarization of $\mathrm{C} 2$. Even a single well-placed IPSP can have a significant effect on the net depolarization elicited by a train of A-spikes in C2. In Figure $13 B$, the occurrence of individual IPSPs in $\mathrm{C} 2$ was monitored by simultaneously recording from a neuron (GF) that exhibits a large EPSP synchronous with an IPSP in C2. Figure $13 B_{1}$ shows the summation of A-spikes in $\mathrm{C} 2$ when it has no inhibitory synaptic input. Figure $13 B_{2}$ gives the summation of the A-spikes when a single IPSP occurs (following the seventh A-spike). Figure $13 B_{3}$ indicates the effect of a series of IPSPs, which dramatically reduce the net depolarization produced by the A-spikes.

\section{Discussion}

The present results indicate that $\mathrm{C} 2$ is a complex mechanoafferent neuron that possesses a number of unusual properties, some of which may contribute to its plastic functions in phenomena such as arousal. It appears to provide proprioceptive information to the CNS, and signals some aspect of a phase of behavioral activity associated with feeding. In addition, it is activated by external mechanoafferent stimulation applied to the perioral zone. While $\mathrm{C} 2$ has a number of properties in common with other mechanoreceptors of invertebrates (Audesirk and Audesirk, 1980a, b; Byrne et al., 1974; Cobbs and Pinsker, 1978; Getting, 1976; Rosen et al., 1982), the overall constellation of properties of this cell distinguishes it from other receptor neurons in Aplysia and other invertebrates. For example, several types of sensory as well as motor neurons that exhibit branch block have been described (Dorsett and Sigger, 1981; Haydon and Winlow, 1982; Spira et al., 1976; Spray et al., 1980a, b; Van Essen, 1973; Yau, 1976), but, unlike C2, these neurons are not blocked when first activated. Rather, the block typically occurs as a consequence of prolonged high-frequency firing. By contrast, $\mathrm{C} 2$ initially is in a nonconducting state. Lowfrequency spike activity is blocked at its entry into the CNS and functions like excitatory synaptic input. If axonal input occurs at sufficient frequency, the cell switches to a transmitting mode and distributes varied synaptic outputs to its follower cells. Once the cell is in the transmitting mode, branch block does not occur as a consequence of normal rates of axon firing but, rather, is easily produced by powerful inhibitory synaptic input, or by the rate of axon firing falling below a threshold value.

\section{Sensory function of $\mathrm{C} 2$}

The conclusion that $\mathrm{C} 2$ functions as an afferent neuron is based on the evidence that the source of the powerful excitatory potentials in $\mathrm{C} 2$ is an axon spike that is an electrotonic reflection of a spike transmitted from one or more peripheral axons of $\mathrm{C} 2$, and that normally does not invade the soma of $\mathrm{C} 2$. Although the evidence provides strong support for the conclusion that $\mathrm{C} 2$ is an afferent neuron, the conclusion that it might be a primary afferent is tentative, since it is based mainly on the observation that peripheral mechanical stimuli are still effective in a solution of low $\mathrm{Ca}^{2+}$, high $\mathrm{Mg}^{2+}$ ions. This solution might not penetrate to the putative peripheral chemical synapses even though it penetrates sufficiently to increase the threshold for the activation of the afferents. Furthermore, there might exist an interposed peripheral electrical junction which would not be blocked by the low $\mathrm{Ca}^{2+}$, high $\mathrm{Mg}^{2+}$ solution.

Although C2 is an afferent neuron, it receives powerful, discrete synaptic input. Several similar instances have been described in other invertebrates. For example, the cerebral ganglion of Tritonia contains a population of mechanoafferent neurons that are activated by stimuli applied to muscles of the buccal mass, and that receive excitatory synaptic input in response to chemosensory stimulation of the oral region (Audesirk 
A

NERVE STIM. (REST. POT.)

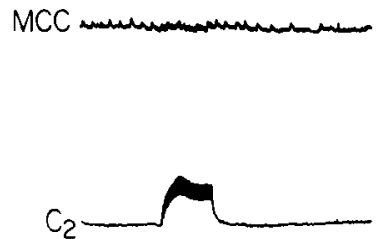

B NERVE STIM. (+5 mV)

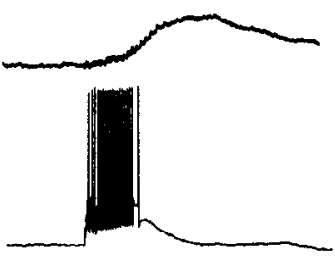

C

INTRACELL. STIM. (REST. POT.)

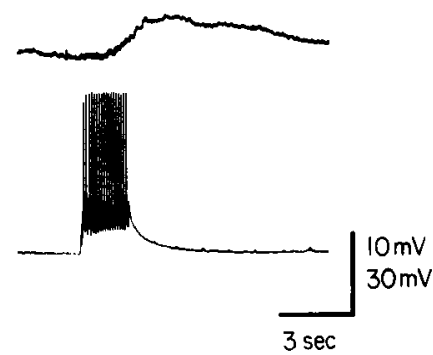

Figure 12. Effects of somatic spikes in neuron $\mathrm{C} 2$ on synaptic transmission to the $\mathrm{MCC}$, an excitatory follower. $A$, With $\mathrm{C} 2$ at resting potential (REST. POT.) stimulation (NERVE STIM.) of the posterior lip nerve produced a burst of A-spikes in C2. These A-spikes did not bring the cell to threshold for producing somatic spikes, and no synaptic potential was seen in the MCC. $B$, When $C 2$ was depolarized by $10 \mathrm{mV}$, nerve stimulation produccd action potentials that invaded the soma of $\mathrm{C} 2$, and a slow EPSP occurred in the MCC. $C$, Ncuron $\mathrm{C} 2$ was held at resting membrane potential and a burst of somatic spikes was produced by injecting brief intracellular current pulses (INTRACELL. STIM.) so that each pulse produced a single action potential at the same rate as the A-spikes in $A$. Under these conditions, a slow depolarizing synaptic potential was recorded in the MCC.

and Audesirk, 1980a, b). Other examples in gastropods are the mechanoafferents that innervate the buccal musculature of $\mathrm{Na}$ vanax (Spray et al., 1980a, b) and the sensory motor salivary burster of Limax (Beltz and Gelperin, 1980). For these afferents, it is not clear under what circumstances they normally fire. In the case of $\mathrm{C} 2$, the neuron is powerfully activated at the end of protraction and throughout the subsequent retraction of the odontophore. The immediate stimulus for activation of $\mathrm{C} 2 \mathrm{dur}$ ing ongoing behavior after food is removed from the lips has not been determined. Since $\mathrm{C} 2$ is readily activated by pressure stimuli applied to the perioral zone, it is likely that $\mathrm{C} 2$ responds to deformation of the perioral tissue when the buccal mass is in a far-forward position or when the jaws close against one another. Since stretching of individual muscles is not a very effective stimulus, it is less likely that $\mathrm{C} 2$ is a muscle afferent, but this possibility cannot be completely excluded.

\section{Histamine as an afferent transmitter}

Since there is considerable evidence that $\mathrm{C} 2$ utilizes histamine as its transmitter (McCaman and Weinreich, 1982; Ono and

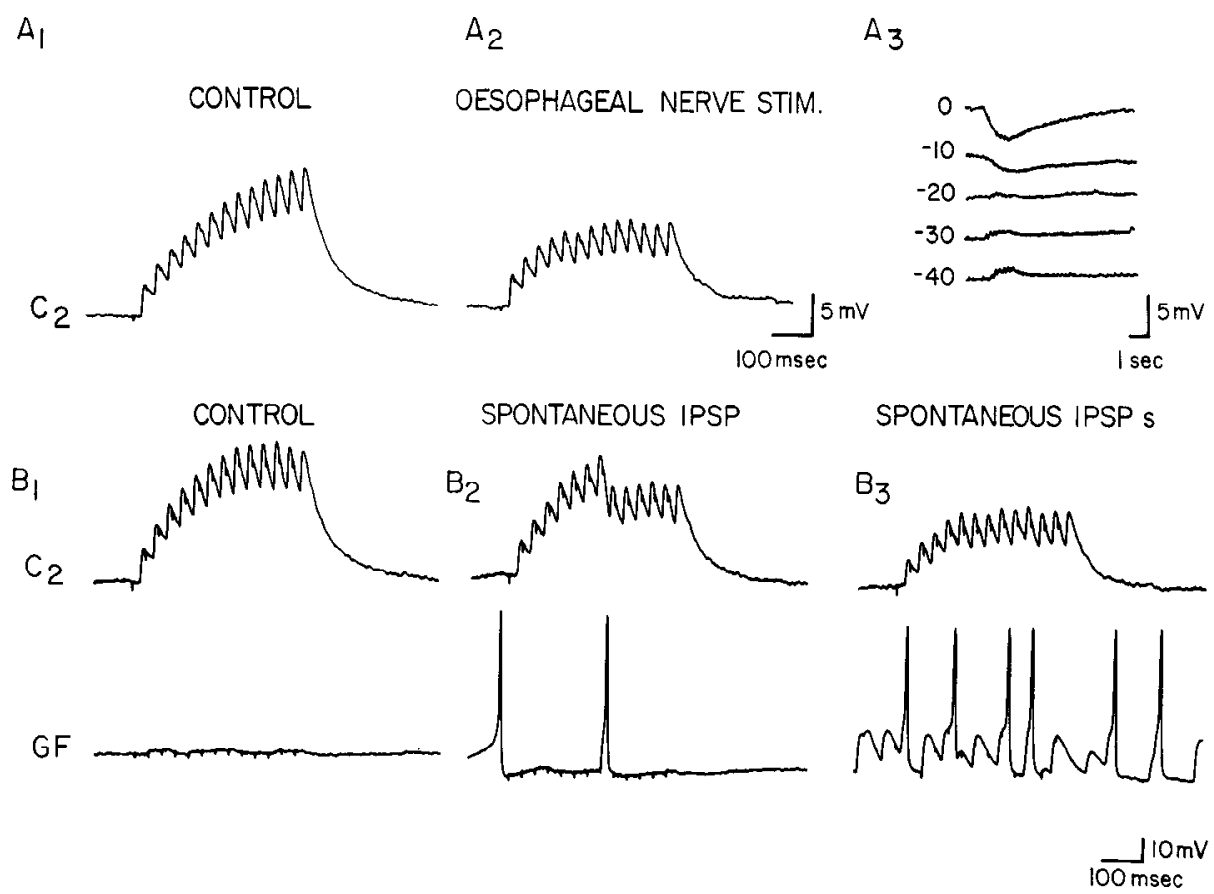

Figure 13. Effect of inhibitory synaptic input on the size and summation of A-spikes in neuron C2. $A_{l}$, A-spikes prior to stimulation of the esophageal nerve (OESOPHAGEAL NERVE STIM.). The A-spikes were elicited by a train of electrical stimuli applied to the posterior lip nerve. $A_{2}$, Summation of A-spikes when the esophageal nerve was tonically stimulated. Note that the amount of summation is reduced. $A_{3}$, Slow IPSP elicited in $\mathrm{C} 2$ by a $1 \mathrm{sec}$ train of electrical stimulation of the esophageal nerve. Hyperpolarization of cell C2 first reduced the amplitude of the IPSP, and then reversed it at approximately $-20 \mathrm{mV}$ from resting potential, which was approximately $-60 \mathrm{mV}$. B, Effect of spontaneously occurring IPSPs on A-spikes in C2. The occurrence of IPSPs in C2 was monitored in the unidentified cell GF, which showed a large EPSP synchronous with an IPSP in C2. $B_{l}$, A-spikes in the absence of spontaneous IPSPs. $B_{2}$, Effect of a single IPSP that occurred during a train of A-spikes. $B_{3}$, Effect of continuous spontaneous IPSPs that occurred during a train of A-spikes. 
McCaman, 1980; Weinreich, 1977, 1979; Wcinrcich and Yu, 1977; Weinreich et al., 1975), our findings suggest that histamine functions as the transmitter of at least one class of afferent fibers in Aplysia. Currently, the only well-established sensory afferent transmitter in invertebrates is acetylcholine, although the numbcr of cascs studicd is relatively small (e.g., Barker et al., 1972; Florey, 1973; Harrow and Sattelle, 1983; Heldman et al., 1979). In Aplysia, the only previously known afferent transmitter is $\mathrm{ACh}$, which is present in identified cells B4 and B5 (Gardner and Kandel, 1972; Ono and McCaman, 1979), which appear to function as muscle mechanoafferents (Fiore and Geppetti, 1981; Jahan-Parwar et al., 1983). Although $\mathrm{C} 2$ is highly unusual and could not be considered a representative afferent neuron, the presence of histamine suggests that ACh is not uniquely associated with afferent transmission in Aplysia or invertebrates in general. Indeed, for the mechanoafferent neurons in the abdominal ganglion of Aplysia, again, ACh does not appear to be the transmitter (V. F. Castellucci, personal communication).

\section{Morphology of $\mathrm{C} 2$}

Cobalt fills of $\mathrm{C} 2$ indicated that it has a number of morphological characteristics that are consistent with its functional properties. The cell sends 3 axons to peripheral nerves that innervate the perioral region. The axons are of small diameter and join a main axon that has considerably greater diameter. The abrupt increase of axonal diameter presumably provides a region of low safety factor, since the large axon will act as a current sink for the relatively small currents generated by the fine peripheral axons. Electron-microscopical studies of the axon of C2 by Schwartz et al. (1986) indicate further axonal specializations that can contribute to the low safety factor at the junction between the peripheral axons and the main process. Finally, the great majority of fine processes of $\mathrm{C} 2$ are located centrally to the region of presumed low safety factor at which the full axon spike fails to actively propagate. The synaptic output of C2 (Bailey et al., 1982) and of other molluscan neurons occurs at such fine processes. Therefore, it is likely that the axonal spike is blocked before reaching the primary synaptic release area. As a consequence, the terminals will receive only small, electrotonically transmitted depolarizations unless the peripheral spike invades the main process. Because the main process is of large diameter, its invasion by an action potential should always be associated with a full action potential in the soma, and a somatic spike should indicate that the terminals of $\mathrm{C} 2$ have been depolarized to a level sufficient to produce transmitter release.

\section{Gating of $C 2$ excitatory input}

Although $\mathrm{C} 2$ is an afferent neuron, in many ways it functions as if it were a secondary interneuron that receives excitatory synaptic input from primary afferent fibers. This is a consequence of the fact that the centripetally transmitted spike of $\mathrm{C} 2$ initially fails to invade the cell body and appears as an A-spike in the soma. The A-spikes function like synaptic input, exhibiting temporal and spatial summation, as well as a type of facilitation. The synaptic properties of the A-spikes are similar to those exhibited by examples of electronic potentials between electrically coupled neurons in the electromotor nucleus of fish (Bennett and Pappas, 1983) and in the neuroendocrine bag cells of Aplysia (Blankenship and Haskins, 1979). In these examples, however, the functional significance of the synaptic electronic potentials is not clear. On the other hand, the synaptic properties of A-spikes in $\mathrm{C} 2$ appear to be of functional significance since the A-spikes alone are ineffective in producing transmitter release-at least for the $\mathrm{MCC}$ and for some inhibitory follower cells of $\mathrm{C} 2$. The morphology of $\mathrm{C} 2$ (see above) suggests that this conclusion is likely to be valid for most or all of the follower cclls of $\mathrm{C} 2$, but we cannot exclude the possibility that at certain follower cells, transmitter release occurs even in the absence of somatic or initial axon spikes.

\section{Gating of synaptic output of $C 2$}

The fact that the synaptic output of $\mathrm{C} 2$ depends upon invasion of the main axonal process or soma has several functional consequences. First, it results in little or no synaptic output unless the frequency of axonal spikes is sufficient to summate and reach threshold for the soma, or initial axon process (regions I and II, Fig. 5). One result of this feature is that $\mathrm{C} 2$ will "ignore" sporadic or low-frequency afferent activity and will only pass on information that is above some threshold of intensity.

A second consequence of the requirement for a central spike is that the output of $\mathrm{C} 2$ can be modulated by synaptic input. Excitatory synaptic input could, in principle, shift the operating characteristic in the direction of increased sensitivity to lowintensity stimulation, whereas inhibitory input will have the opposite effect. We have not observed reliable excitatory input to $\mathrm{C} 2$ but, as previously discussed, the cell receives several types of powerful inhibitory inputs, including discrete phasic IPSPs that occur during each cycle of the feeding motor program as well as tonic IPSPs that occur when the esophageal nerve is electrically stimulated. Phasic IPSPs in C2 are due, at least in part, to the activity of an identified interneuron located in the buccal ganglion. This interneuron fires in phase with a feeding motor program and provides a corollary discharge to the cerebral ganglion (H. J. Chiel, K. R. Weiss, and I. Kupfermann, unpublished observations). The corollary discharge insures that sensory information transmitted via activity of $\mathrm{C} 2$ during a particular phase of the motor program will be "ignored" by the CNS. Phase-specific gating of axonal branches of a motor neuron has been described in the lobster nervous system (Nagy et al., 1981), and phasic gating of sensory information has been reported for several systems in vertebrates and invertebrates (e.g., Bandler, 1984; Camhi and Hinkle, 1974; Chapin and Woodward, 1982; Evoy, 1976; Forssberg et al., 1977; Gellman et al., 1985; Murphey and Palka, 1974; Reichert and Rowell, 1985; Russell, 1971). In Aplysia, this type of mechanism may operate as a kind of highly effective presynaptic inhibition at the level of a primary afferent. A form of corollary discharge resulting in presynaptic inhibition of mechanoafferents has also been described in the crayfish (Krasnc and Bryan, 1973), but the mechanism (Kennedy et al., 1974) appears to be different from that operating at $\mathrm{C} 2$. Furthermore, in the crayfish, the presynaptic inhibition serves to protect the afferent synapse from synaptic depression, whereas this function is unlikely in the case of $\mathrm{C} 2$, whose synaptic outputs do not appear to exhibit any synaptic depression within physiological limits.

The location of the somata of the cells that provide tonic slow inhibition to $\mathrm{C} 2$ is not known. Since tonic inhibition can be evoked by stimulation of the esophageal nerves, it is possible that this inhibition plays a role in the process of food satiation, which in Aplysia is largely the result of mechanostimulation of the gut (Susswein and Kupfermann, 1975a, b). The inhibitory input from the esophageal nerve raises the interesting possibility that one type of interoceptor, which monitors a state such as satiation, modulates in turn another type of interoceptor (C2) concerned with monitoring consummatory motor activity. Gillette et al. (1978) have reported that several types of behavioral inhibition of feeding in the mollusk Pleurobranchaea are associated with inhibition at the level of feeding command neurons, and perhaps earlier in the circuit. Our findings suggest that inhibitory behavioral states, evoked either by satiation or by noxious peripheral sensory stimulation, may be associated with inhibitory activity that may operate at the level of sensory input (see also Audesirk and Audesirk, 1980b). 


\section{References}

Audesirk, G., and T. Audesirk (1980a) Complex mechanoreceptors in Tritonia diomedea. I. Responses to mechanical and chemical stimuli. J. Comp. Physiol. 141: 101-109.

Audesirk, G., and T. Audesirk (1980b) Complex mechanoreceptors in Tritonia diomedea. II. Neuronal correlates of a change in behavioral responsiveness. J. Comp. Physiol. 141: 111-122.

Bailey, C. H., M. C. Chen, K. R. Weiss, and I. Kupfermann (1982) Ultrastructure of a histaminergic synapse in Aplysia. Brain Res. 238: 205-210.

Bandler, R., ed. (1984) Modulation of Sensorimotor Activity During Alterations in Behavioral States, Alan R. Liss, New York.

Barker, D. L., E. Herbert, J. G. Hildebrand, and E. A. Kravitz (1972) Acetylcholine and lobster sensory neurones. J. Physiol. (Lond.) 226: 205-229.

Beltz, B., and A. Gelperin (1980) Mechanisms of peripheral modulation of salivary burster in Limax maximus: A presumptive sensorimotor neuron. J. Neurophysiol. 44: 675-686.

Bennett, M. V. L., and G. D. Pappas (1983) The electromotor system of the stargazer: A model for integrative actions at electrotonic synapses. J. Neurosci. 3: 748-761.

Blankenship, J. E., and J. T. Haskins (1979) Electrotonic coupling among neuroendocrine cells in Aplysia. J. Neurophysiol. 42: 347355.

Byrne, J., V. Castellucci, and E. R. Kandel (1974) Receptive fields and response properties of mechanoreceptor neurons innervating siphon skin and mantle shelf in Aplysia. J. Neurophysiol. 37: 10411064.

Camhi, J. M., and M. Hinkle (1974) Response modification by the central flight oscillator of locusts. J. Exp. Biol. 60: 477-492.

Chapin, J. K., and D. J. Woodward (1982) Somatic sensory transmission to the cortex during movement: Phasic modulation over the locomotor step cycle. Exp. Neurol. 78: 670-684.

Chiel, H. J., K. R. Weiss, and I. Kupfermann (1986) An identified histaminergic neuron modulates feeding motor circuitry in Aplysia. J. Neurosci. 6: 2427-2450.

Cobbs, J. S., and H. M. Pinsker (1978) In vivo responses of paired giant mechanoreceptor neurons in Aplysia abdominal ganglion. $J$. Neurobiol. 9: 121-141.

Dorsett, D. A., and J. N. Sigger (1981) Sensory fields and properties of the oesophageal proprioceptors in the mollusc, Philine. J. Exp. Biol. 94: 77-93.

Evoy, W. H. (1976) Modulation of proprioceptive information in crustacea. In Neural Control of Locomotion, R. M. Herman, S. Grillner, P. S. G. Stein, and D. G. Stuart, eds., pp. 617-645, Plenum, New York.

Fiore, L., and L. Geppctti (1981) Ncural control of buccal mass activity in Aplysia. Advances in Physiological Sciences, Vol. 23, In Neurobiology of Invertebrates, J. Salanki, ed., pp. 201-223, Pergamon, New York.

Florey, E. (1973) Acetylcholine as sensory transmitter in crustacea: New evidence from experiments demonstrating release of ACh during sensory stimulation. J. Comp. Physiol. 83: 1-16.

Forssberg, H., S. Grillner, and S. Rossignol (1977) Phasic gain control of reflexes from the dorsum of the paw during spinal locomotion. Brain Res. 132: 121-139.

Gardner, D., and E. R. Kandel (1972) Diphasic postsynaptic potential: A chemical synapse capable of mediating conjoint excitation and inhibition. Science 176: 675-678.

Gellman, R., A. R. Gibson, and J. C. Houk (1985) Inferior olivary neurons in the awake cat: Detection of contact and passive body displacement. J. Neurophysiol. 54: 40-60.

Getting, P. A. (1976) Afferent neurons mediating escape swimming of the marine mollusc, Tritonia. J. Comp. Physiol. 110: 271-286.

Gillette, R., M. P. Kovak, and W. J. Davis (1978) Command neurons in Pleurobranchaea receive synaptic feedback from the motor network they excite. Science 199: 798-801.

Gotoh, H., and J. H. Schwartz (1982) Specificity of axonal transport in C2, a histaminergic neuron of Aplysia californica. Brain Res. 242: 87-98.

Harrow, I. D., and D. B. Satelle (1983) Acetylcholine receptors on the cell body membrane of giant interneurone 2 in the cockroach, Periplaneta americana. J. Exp. Biol. 105: 339-350.
Haydon, P. G., and W. Winlow (1982) Multipolar neurones of Lymnaea stagnalis. I. Multiple spike initiation sites and propagation failure allow neuronal compartmentalization. J. Comp. Physiol. 147: 503-510.

Heldman, E., Y. Grossman, T. P. Jerussi, and D. L. Alkon (1979) Cholinergic features of photoreceptor synapses in Hermissenda. J. Neurophysiol. 42: 153-165.

Jahan-Parwar, B., A. H. Wilson, Jr., and S. M. Fredman (1983) Role of proprioceptive reflexes in control of feeding muscles of Aplysia. J. Neurophysiol. 49: 1469-1480.

Kennedy, D., R. L. Calabrese, and J. J. Wine (1974) Presynaptic inhibition: Primary afferent depolarization in crayfish neurons. Science 186: 451-454.

Koch, U. T., J. Koester, and K. R. Weiss (1984) Neuronal mediation of cardiovascular effects of food arousal in Aplysia. J. Neurophysiol. 51: 126-135.

Krasne, F. B., and J. S. Bryan (1973) Habituation: Regulation through presynaptic inhibiton. Science 182: 590-592.

McCaman, R. E., and D. Weinreich (1982) On the nature of histamine mediated slow hyperpolarizing synaptic potentials in identified molluscan neurones. J. Physiol. (Lond.) 328: 485-506.

Murphey, R. K., and J. Palka (1974) Efferent control of cricket giant fibres. Nature 248: 249-251.

Nagy, F., P. S. Dickinson, and M. Moulins (1981) Rhythmical synaptic control of axonal conduction in a lobster motor neuron. J. Neurophysiol. 45: 1109-1124

Ono, J. K., and R. E. McCaman (1979) Measurement of endogenous transmitter levels after intracellular recording. Brain Res. 165: 156160.

Ono, J. K., and R. E. McCaman (1980) Identification of additional histaminergic neurons in Aplysia: Improvement of single cell isolation techniques for in tandem physiological and chemical studies. Neuroscience $5: 835-840$.

Reichert, H., and C. H. F. Rowell (1985) Integration of nonphaselocked exteroceptive information in the control of rhythmic flight in the locust. J. Neurophysiol. 53: 1201-1218.

Rosen, S. C., K. R. Weiss, and I. Kupfermann (1979) Response properties and synaptic connections of mechanoafferent neurons in cerebral ganglion of Aplysia. J. Neurophysiol. 42: 954-974.

Rosen, S. C., K. R. Weiss, J. L. Cohen, and I. Kupfermann (1982) Interganglionic cerebral-buccal mechanoafferents of Aplysia: Receptive fields and synaptic connections to different classes of neurons involved in feeding behavior. J. Neurophysiol. 48: 271-288.

Russell, I. J. (1971) The role of the lateral-line efferent system in Xenopus laevis. J. Exp. Biol. 54: 621-641.

Schwartz, J. H., A. Elste, E. Shapiro, and H. Gotoh (1986) Biochemical and morphological correlates of transmitter type in $\mathrm{C} 2$, an identified histaminergic neuron in Aplysia. J. Comp. Neurol. 245: 401-421.

Shapiro, E., V. F. Castellucci, and E. R. Kandel (1980) Presynaptic membrane potential affects transmitter release in an identified neuron in Aplysia by modulating the $\mathrm{Ca}^{2+}$ and $\mathrm{K}^{+}$currents. Proc. Natl. Acad. Sci. USA 77: 629-633.

Shimahara, T., and L. Tauc (1975) Multiple interneuronal afferents to the giant cells in Aplysia. J. Physiol. (Lond.) 247: 299-319.

Spira, M. E., Y. Yarom, and I. Parnas (1976) Modulation of spike frequency by regions of special axonal geometry and by synaptic inputs. J. Neurophysiol. 39: 882-899.

Spray, D. C., M. E. Spira, and M. V. L. Bennett (1980a) Peripheral fields and branching patterns of buccal mechanosensory neurons in the opisthobranch mollusc, Navanax inermis. Brain Res. 182: 253. 270.

Spray, D. C., M. E. Spira, and M. V. L. Bennett (1980b) Synaptic connections of buccal mechanosensory neurons in the opisthobranch mollusc, Navanax inermis. Brain Res. 182: 271-286.

Susswein, A. J., and I. Kupfermann (1975a) Bulk as a stimulus for satiation in Aplysia. Behav. Biol. 13: 203-209.

Susswein, A. J., and I. Kupfermann (1975b) Localization of bulk stimuli underlying satiation in Aplysia. J. Comp. Physiol. 101: 309328.

Van Essen, D. C. (1973) The contribution of membrane hyperpolarization to adaptation and conduction block in sensory neurones of the leech. J. Physiol. (Lond.) 230: 509-534.

Weinreich, D. (1977) Synaptic responses mediated by identified histamine-containing neurones. Nature 267: 854-856.

Weinreich, D. (1978) Histamine-containing neurons in Aplysia. In 
Biochemistry of Characterised Neurons, N. N. Osborn, ed., pp. 153175, Pergamon, Oxford, UK.

Weinreich, D. (1979) gamma-Glutamylhistamine: A major product of histamine metabolism in ganglia of the marine mollusk, Aplysia californica. J. Neurochem. 32: 363-369.

Weinreich, D., and Y.-T. Yu (1977) The characterization of histidine decarboxylase and its distribution in nerves, ganglia and in single neuronal cell bodies from the CNS of Aplysia californica. J. Neurochem. 28: 361-369.

Weinreich, D., C. Weiner, and R. McCaman (1975) Endogenous levels of histamine in single neurons isolated from CNS of Aplysia californica. Brain Res. 84: 341-345.

Weiss, K. R., H. J. Chiel, and I. Kupfermann (1983) The histaminergic neuron C2 of Aplysia is a mechanoafferent whose output can be gated synaptically. Soc. Neurosci. Abstr. 9: 913.

Weiss, K. R., E. Shapiro and I. Kupfermann (1986a) Modulatory synaptic actions of an identified histaminergic neuron on the serotonergic metacerebral cell of Aplysia. J. Neurosci. 6: 2393-2402.

Weiss, K. R., H. J. Chiel, U. Koch, and I. Kupfermann (1986b) Activity of an identified histaminergic neuron, and its possible role in arousal of feeding behavior in semi-intact Aplysia. J. Neurosci. 6: 2403-2415.

Yau, K.-W. (1976) Receptive fields, geometry and conduction block of sensory neurones in the central nervous system of the leech. J. Physiol. (Lond.) 263: 513-538. 